\title{
THE PROPOSAL OF AN ADAPTED PRE-EXERCISE SCREENING TOOL FOR THE RECRUITMENT OF THE ELDERLY IN RESEARCH WITH RESISTANCE TRAINING
}

report from scientific meetings

(1) University School of Physical Education in Wroclaw

DOI: https://doi.org/10.5114/hm.2021.98460

\section{BRUNO SARAIVA $^{1}$, DAHAN DA CUNHA NASCIMENTO ${ }^{1,2}$, IVO VIEIRA DE SOUSA NETO ${ }^{3}$, RENATO VALDUGA ${ }^{4}$, ADAMOR DA SILVA LIMA ${ }^{1}$, JEFFREY M. WILLARDSON ${ }^{5}$, JONATO PRESTES ${ }^{1}$, GUILHERME BORGES PEREIRA ${ }^{6}$}

${ }^{1}$ Graduate program of Physical Education, Catholic University of Brasilia, Federal District, Brazil

${ }^{2}$ Department of Physical Education, University Centre of the Federal District, Brasilia, Brazil

${ }^{3}$ Graduate program of Sciences and Technology of Health, University of Brasilia, Brasilia, Brazil

${ }^{4}$ Base Hospital of the Federal District, Brasilia, Brazil

${ }^{5}$ Montana State University Billings, Billings, MT, United States of America

${ }^{6}$ Department of Physiological Sciences, Federal University of São Carlos, São Carlos, Brazil

\begin{abstract}
Purpose. The purpose was to investigate an adapted pre-exercise screening tool to evaluate musculoskeletal injury in elderly women before starting a resistance training (RT) program, and to verify whether the tool could detect subjects not eligible for RT research on the basis of the RT program injury rate.

Methods. Overall, 74 subjects participated in an orthopaedic evaluation by a certified physical therapist. History was taken of injury, dysfunction and related musculoskeletal diseases, surgeries, fractures, and falls. A series of tests was applied to identify potential risks and injuries.

Results. Owing to history of falls and fractures and poor mobility and performance in physical function tests, 14 patients were excluded. The most common deficits were: rotator cuff tendinopathy $(n=2)$, knee osteoarthritis $(n=3)$, both rotator cuff tendinopathy and knee osteoarthritis $(n=3)$, lumbar discopathy $(n=2)$, cervicalgia $(n=1)$, back pain sciatica $(n=1)$, rotator cuff injury $(n=1)$, wrist and knee pain $(n=1)$. The main joints affected were: knees $(n=7)$, shoulders $(n=6)$, lumbar spine $(n=5)$, thoracic spine $(n=1)$, and cervical spine $(n=2)$. Overall, 60 elderly women started the RT program, while 39 had an adherence of $>90 \%$.
\end{abstract}

Conclusions. The adapted tool was effective in recruiting subjects, who had a lower injury rate during RT. It helped to identify musculoskeletal dysfunction and improved safety and adherence outcomes in elderly women.

Key words: orthopaedic evaluation, musculoskeletal dysfunction, physical function tests

\section{Introduction}

Resistance training (RT) is considered an effective modality to prevent frailty in the elderly, and consists of exercises for the upper and lower limbs with progressive load increases designed to improve strength, power, balance, and functional capacity [1]. Moreover, RT should be performed consistently, individually tailored, progressive, educational, and enjoyable [1].

There is evidence that older adults can substantially increase their strength, muscle power, muscle quality, muscular endurance, body composition, and bone mineral density in response to RT [2]. Notably, dynamic RT training alone can elicit blood pressure reductions that are comparable with or greater than those previously reported with aerobic training among hypertensive subjects [3]. Furthermore, a previous study demonstrated evidence supporting exercise prescription as part of treatment for metabolic syndrome disorders, heart and pulmonary diseases, muscle, bone, and joint diseases, cancer, and depression [4].

Although RT is important for elderly subjects, with-

Correspondence address: Bruno Saraiva, Physical Education Department, Campus I - QS 07 - Lote 01 - EPCT - Aguas Claras - Brasilia - Zip code: 71966-700, Brazil, e-mail: brunnosaraiva87@gmail.com

Received: April 21, 2019

Accepted for publication: February 14, 2020

Citation: Saraiva B, da Cunha Nascimento D, de Sousa Neto IV, Valduga R, da Silva Lima A, Willardson JM, Prestes J, Pereira GB. The proposal of an adapted pre-exercise screening tool for the recruitment of the elderly in research with resistance training. Hum Mov. 2021;22(1):16-26; doi: https://doi.org/10.5114/hm.2021.98460. 
out proper prescription, it can even increase the potential for musculoskeletal injuries. According to resolution 466/2012 proposed by the National Health Council from Brazil [5], researchers must provide full assistance for complications and injury resulting directly or indirectly from research that does not provide financial compensation to subjects. This resolution also guarantees immediate assistance to subjects without cost, and indemnity to repair the damage caused by the research protocol. Thus, the strategies adopted to ensure the safety of the subjects and to minimize the risk of ethical violations make selection of inclusion criteria especially critical in research design.

Morrow et al. [6] observed that musculoskeletal injury of community-dwelling women rose by $44 \%$ in those meeting the $>150$-min and by $66 \%$ in those exceeding the 300-min physical activity guidelines. Hootman et al. [7] also evaluated the predictors of lower extremity injury among recreationally active adults that reported regular participation in a run/walk/jog program. Their results indicated that previous lower extremity injury was the strongest predictor of a lower extremity injury in men. However, few studies have referred to RT safety in the geriatric age group and the importance of preliminary health testing to identify subjects considered not eligible for RT research.

The assessment for enrolment of elderly subjects requires special consideration of hearing impairment, chronic illness, and reduced cognitive capacity [8]. A traditional recruitment plan may result in a large number of ineligible subjects, which will ultimately affect the sample size and generalizability of the results [9]. Moreover, a well-planned recruitment strategy is crucial to promote participants' safety and adherence [8].

Regardless of a well-executed recruitment plan, adherence might be affected by other factors. For example, subjects receiving financial compensation might exhibit greater motivation than those who are uncompensated [10]. Interestingly, males have been shown to be more interested in financial compensation, whereas females often participate for the benefit of the cause [10]. To note, elderly subjects may experience more benefits from participation than younger subjects in terms of health and psychological well-being [11].

Adherence to exercise programs in older people is influenced by accessibility, format of the training program, number of appointments, travel costs, enjoyment, fitness and health benefits [12, 13]. However, research involving high-intensity training might be more susceptible to attrition in elderly subjects owing to greater exertion, associated physical discomfort, and injury during training $[13,14]$.
Researchers are aware that with proper preparation, strength tests can be a safe assessment tool for the geriatric population. However, elderly subjects recruited during research with no prior RT experience might be at a higher risk for injuries. In a previous study with middle-aged participants with no RT experience, 2 subjects sustained injuries (back injury and a rib fracture) during a 1-repetition maximum (RM) test [15]. Secondly, when elderly subjects volunteer to participate in a study, strength testing of multiple muscle groups on the same day may increase the number of areas stressed and the likelihood of injury. Furthermore, an injury during strength testing might be related to a previous orthopaedic problem not detected in the screening process. Therefore, strategies to ensure the safety of subjects under conditions of higher exercise intensity should be considered [16].

Many current pre-screening models to ensure participants' safety exist, including the Physical Activity Readiness Questionnaire and You (PAR-Q) and the Physical Activity Readiness Medical Examination (PARmed-X); these were the Canada's primary preparticipation screening tools for physical activity [17]. Thus, when elderly subjects provide a positive response in PAR-Q, they are referred to consult their physician for clearance. In the research environment, our practice demonstrates that PAR-Q is not sufficient to identify subjects not eligible for RT practice. It is important to note that our criticism of PAR-Q is based on daily practice rather than evidence.

In this context, physical therapy evaluation involves an anamnesis and physical examination to analyse the functionality of the subjects and to determine potential chronic musculoskeletal disorders [18], especially during RT with progressively higher intensities [19]. The basic tenet behind the inclusion of a physical therapy professional and not PAR-Q is that this procedure could predict and thereby prevent adverse musculoskeletal injuries related to 10-RM or 1-RM tests during an RT program. Moreover, shoulders and arms are the most commonly injured segments during both weightlifting and other recreational activities [20], which suggests that physical therapy evaluation would be beneficial as part of the screening process, especially in elderly subjects.

Although participants respond to specific questions regarding inclusion and exclusion criteria, these questions may not be sufficient to ensure safety and to avoid musculoskeletal injuries during RT. Some studies described recruitment strategies to assist researchers in promoting greater adherence [8, 10, 21]. However, no previous study has reported the use of a 
specific physical therapy evaluation as a recruitment strategy for RT in the elderly. This information would be valuable as rigorous evaluation can help to assess functional limitations, potentially avoid surgery, and prevent injuries, along with better therapeutic exercise prescription. These benefits are important to promote the recruitment, safety, and adherence of elderly during research involving RT.

Therefore, the purpose of the present study was to demonstrate the significance of an adapted pre-exercise screening tool to evaluate the presence of musculoskeletal injury in elderly women before starting a RT program. The initial hypothesis was that the preexercise screening tool would be able to detect ineligible subjects for RT research and account for a lower injury rate during a RT program [22].

\section{Material and methods}

\section{Subjects}

For a better comprehension of this study, the reader must refer to our previous study, where the adapted pre-exercise screening tool was applied [22] and subjects were submitted to a resting and exercise electrocardiogram, manual blood pressure measurements, body composition assessment via dual-energy $\mathrm{X}$-ray absorptiometry, fitness functional tests, and orthopaedic evaluation by an experienced physiotherapist before participation in the study. Following the initial examination, the subjects underwent a 2 -week familiarization period to practise the exercises included in the RT program. Initially, 152 subjects from the Community Social Center for the elderly from the Catholic University of Brasilia listened to an explanatory lecture regarding the objectives and benefits of the study. From among these, 90 older women met the inclusion criteria (female, age $\geq 60$ years, characterized as non-hypertensive or with controlled essential hypertension). A total of 62 individuals who had an inflammatory disease (e.g. rheumatoid arthritis), hemodynamic disease (e.g. uncontrolled hypertension), osteomyelitis (e.g. arthrosis), or blood clotting (e.g. thrombocytopenia) were excluded.

The subjects' characteristics are presented in Table 1 . The women completed a quality of life questionnaire and underwent anthropometric measurements, body composition assessment by dual-energy X-ray absorptiometry, blood pressure evaluation, a cardiopulmonary exercise test, and functional capacity tests (handgrip strength, timed up-and-go, sitting-rising tests) when authorized by a cardiologist.
Table 1 . Elderly women characteristics $(n=90)$

\begin{tabular}{lcrr}
\hline Parameter & Mean $\pm S D$ & Minimum & Maximum \\
\hline Age (years) & $68.10 \pm 6.00$ & 59.00 & 87.00 \\
Height $(\mathrm{m})$ & $1.54 \pm 0.06$ & 1.41 & 1.71 \\
Body mass $(\mathrm{kg})$ & $68.50 \pm 11.30$ & 47.50 & 99.30 \\
BMI $\left(\mathrm{kg} / \mathrm{m}^{2}\right)$ & $28.80 \pm 4.30$ & 20.00 & 39.28 \\
Body fat $(\%)$ & $39.80 \pm 6.10$ & 25.70 & 51.30 \\
\hline
\end{tabular}

$S D$ - standard deviation, BMI - body mass index

\section{Instrument}

The physical therapy evaluation was conducted before participation in the research, in accordance with resolution 466/2012 of the National Council of Health, to identify potential risks of musculoskeletal injury/ disorders that would constitute contraindications for a RT program [23]. The evaluation was performed by a certified physical therapist (Renato Valduga, graduated in physiotherapy, master and $\mathrm{PhD}$ in physical education). The assessment consisted of an interview in which the subjects were asked about their injury history, dysfunctions and musculoskeletal diseases (e.g. osteoarthritis, osteophytes, tendinopathy), surgeries, and history of fractures and/or falls during the previous year.

The pre-exercise screening tool used in the study was adapted from previous studies. Thus, there was no necessity of validation. Items of Table II and Table III from the study by Posner et al. [24] were used for steps 2 and 3 in the pre-exercise screening tool. Studies by Balady et al. [25] and American College of Sports Medicine [2] imply that recommendations from the American Heart Association and American College of Sports Medicine (ACSM) for cardiovascular screening were applied for steps 2 and 3 in the pre-exercise screening tool, and the New Zealand pre-screening guide [26] was used as a reference for the design of steps 1-6 of the adapted pre-exercise screening assessment. The only innovation introduced in our tool was the inclusion of a physical therapy assessment (step 7), based on a guideline for functional capacity evaluation of people with medical conditions [23].

Moreover, the following questions were involved: (1) Do you have any history of injuries and diseases? (2) Have you had any previous surgery related to the locomotor system? (3) Do you have any history of falls in the recent months; if so, how many? (4) Do you have any difficulty in performing daily living activities? (For more details, see the adapted pre-exercise screening tool attached as an appendix). In the case of positive responses, further special testing was performed by 
the physical therapist to analyse the functional capacity of a person to perform work-related tasks [23].

Some important information about the physical therapist (step 7) must be addressed. As mentioned by Hart et al. [23], the best that a physical therapist can do is to select a test that reflects the needs and abilities of the subject. Thus, the purpose of the physical therapist was to determine what the individual could do in the RT program on a safe and dependable basis. The order of the physical therapist's procedures was as follows [23]:

1. Take a history of the subject's medical status.

2. Perform a pre-exercise screening examination.

3. Perform functional testing to evaluate baseline capacity (using common physical demands such as sitting, standing, walking, balancing, kneeling, stooping, crouching, reaching, lifting, carrying, pushing, pulling, grasping, and pinching).

4. Evaluate RT capacity: if the execution of specific exercises to which the individuals will be submitted are known, and if these exercises were tested in the RT program familiarization process.

5. Evaluate work capacity: simulation of a moderate intensity RT program (10-12-RM) during the familiarization process is introduced to determine the individual's potential to withstand the basic demands of the RT program.

6. Predict rather than directly measure the participants' potential to sustain work-related tasks.

7. In the case of identified problems, exclude a subject and refer them to medical services for diagnosis and specific treatment.

\section{Resistance training procedures}

The RT program consisted of a linear periodized model adapted from a previous study among elderly [27]. For more information about RT procedures, the reader is referred to our previous publication [22]. All subjects performed exercises for the lower and upper limbs as follows: leg press, chest press, knee extension, seated row, and knee flexion. The elderly women were familiarized with the RT with 2 sets of 15 repetitions with a 1-minute rest interval between the sets, and exercises over 2 weeks [28]. The RT lasted 10 weeks, with two RT sessions performed per week, with a minimum of 24 hours between sessions. The mean duration of training sessions in each mesocycle was $34 \mathrm{~min}$ (T1), $42 \mathrm{~min}$ (T2), $43 \mathrm{~min}$ (T3), and $48 \mathrm{~min}$ (T4) [22]. In the first 3 weeks (T1), 3 sets of 12-14 RM with 60-s rest intervals were performed; in weeks 4-6 (T2), 3 sets of 10-12 RM with 80-s rest intervals were performed; in weeks 7-8 (T3), 3 sets of 8-10 RM with 100 -s rest intervals were performed; and in weeks 9-10 (T4), 3 sets of 6-8 RM with 120-s rest intervals were performed [22]. When the subjects performed more than two repetitions in the $3^{\text {rd }}$ set beyond the RM zone prescribed, the loads were adjusted. In all weeks, repetitions were performed close to concentric failure at the intensities indicated. The loads were monitored in each session. The list and order of exercises were as follows: (1) machine leg press; (2) machine chest press; (3) machine leg extension; (4) machine low row; and (5) machine leg curl. During the sessions, the subjects commonly reported tiredness and difficulty of completing the proposed repetition range in the $3^{\text {rd }}$ set. The elderly women were instructed to perform each repetition at a moderate speed (ca. $2 \mathrm{~s}$ for the concentric phase and $2 \mathrm{~s}$ for the eccentric phase) and to avoid the Valsalva manoeuvre [22]. The participants maintained the prescribed intake of their medications and were encouraged to preserve their usual dietary consumption and to avoid extraordinary physical activity during the 10 weeks of the RT program [22].

\section{Ethical approval}

The research related to human use has complied with all the relevant national regulations and institutional policies, has followed the tenets of the Declaration of Helsinki, and has been approved by the Research Ethics Committee of the Catholic University of Brasilia (protocol No.: 45648115.8.0000.5650/2016).

\section{Informed consent}

Informed consent has been obtained from all individuals included in this study.

\section{Results}

Two subjects were excluded owing to electrocardiography alterations exhibited during the cardiopulmonary exercise test and one was excluded because of high resting blood pressure. Thus, 87 elderly women started the familiarization period for RT. During this period, 13 subjects dropped out of the research for personal reasons $(n=1)$, vacation $(n=2)$, leg pain $(n=1)$, shoulder pain $(n=1)$, and for reasons not specified $(n=8)$. Before conducting the 10-RM testing, the subjects underwent a detailed musculoskeletal evaluation by a physical therapist.

After the anamnesis, the physical therapist performed special functional tests to identify potential risks and injuries. A total of 74 elderly women were examined in the physical assessment laboratory. This 


\section{HUMAN MOVEMENT}

B. Saraiva et al., Physical therapy and the elderly

resulted in the exclusion of an additional 14 subjects (Figure 1) on the basis of history of falls and fractures, as well as poor mobility and performance in physical function tests (e.g. sitting-rising test and time to support unipedal position).

The most common problems identified were: rotator cuff tendinopathy $(n=2)$, knee osteoarthritis $(n=3)$, both rotator cuff tendinopathy and knee osteoarthritis $(n=3)$, lumbar discopathy $(n=2)$, cervicalgia $(n=1)$, back pain sciatica $(n=1)$, rotator cuff injury $(n=1)$, wrist and knee pain $(n=1)$. The main affected joints were: knees $(n=7)$, shoulders $(n=6)$, lumbar spine $(n=5)$, thoracic spine $(n=1)$, and cervical spine $(n=2)$. Furthermore, when the physiotherapist asked about the origin of the related pain, some subjects reported history of falls and/or fracture and/or luxation in the same body segment.

The physical therapy evaluation also confirmed reports of a herniated disc, osteophytosis and bursitis of the shoulder, hip, and knees, which were related to difficulties in performing daily living activities; some participants had already lived with these mus- culoskeletal disorders for 10 years. Overall, 60 elderly women started the RT program, while 39 had an adherence of $>90 \%$ (Figure 1 ). A total of 21 subjects abandoned the research owing to personal reasons, and a lower rate of musculoskeletal injuries occurred during the RT program. During the 10 -week RT program, two elderly subjects withdrew from the study because of low back pain and knee joint swelling [22].

\section{Discussion}

The cost-effective and safe recruitment of elderly subjects is essential to geriatric research. This age group is particularly challenging to recruit but careful procedure planning and ongoing evaluation can overcome these difficulties. A pre-exercise screening tool for the elderly that includes physical therapy evaluation before RT participation is a crucial factor to reduce injury risk during training and consequently contribute to the safety and adherence of subjects. Owing to the inclusion of step 7 (see the Instrument section) in our pre-screening exercise tool, during

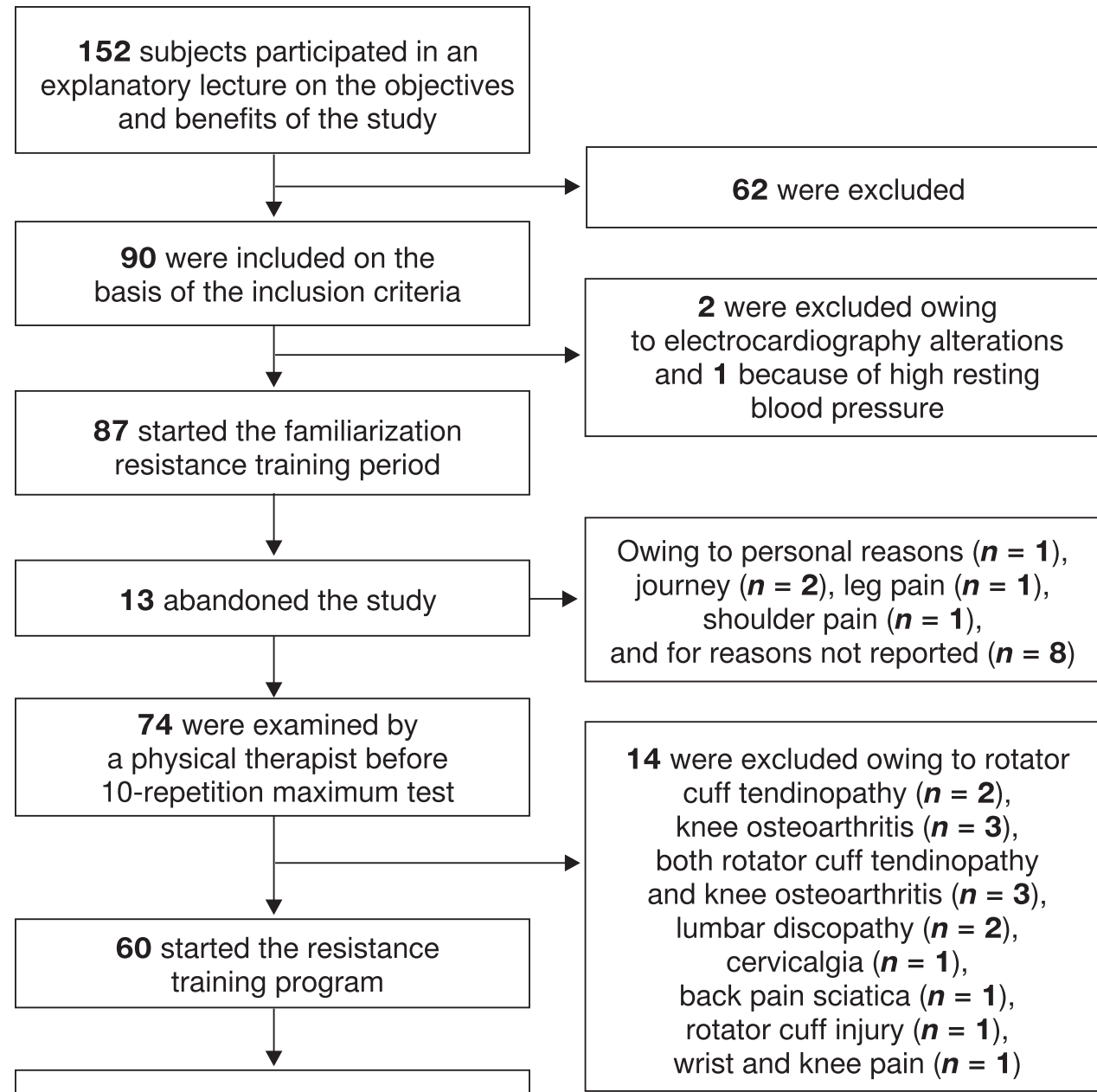

39 had adherence $>90 \%$

Figure 1. Flowchart describing the subjects' enrolment and allocation 
the 10-week RT program, only two elderly subjects dropped out from the study because of low back pain and knee joint swelling during the $1^{\text {st }}$ mesocycle [22]. However, these two injuries were not the type that would represent life-threatening pathology, and both elderly subjects were able to resume routine physical activities after a recovery period of 2 weeks. Thus, the adapted pre-exercise screening tool successfully detected subjects not eligible for RT research, and may have contributed to the lower injury rate in the study which was previously published by our research group [22].

Overall, five subjects were diagnosed with rotator cuff tendinopathy, and one with rotator cuff rupture. Tendinopathy is a generic term that includes several diagnoses (e.g. subdeltoid bursitis, long head biceps tendinitis/tendinosis) and may result in functional limitations in daily life and poor health-related quality of life [29]. Rotator cuff tendinopathy leads to functional limitations such as decreased shoulder range of motion and decreased shoulder and arm strength [30]. The difference in muscle strength between a healthy shoulder and an injured shoulder in patients with rotator cuff tendinopathy probably results in a difficulty to apply the correct technique during moderate-high intensity resistance exercises that requires flexion and extension of the shoulder [30]. In turn, rotator cuff rupture produces changes in kinematic function, accompanied by shoulder pain and atrophy of the surrounding musculature [31]. Initial treatment may not always be surgical, depending on the activity level and tear size [32].

A total of six elderly women were diagnosed with knee osteoarthritis, the most common form of arthritis, which causes pain and decreased physical function [33]. Gonçalves et al. [34] reported that people with moderate knee osteoarthritis presented kinematic changes of the pelvis, hip, knee, and ankle in the sagittal plane during an ascending stairs task versus both control and mild knee osteoarthritis groups. Nguyen et al. [35] suggested in a critical narrative review that specific RT for the lower limb might reduce pain and improve physical function in cases of knee osteoarthritis. Additionally, Ciolac and Greve [36] proposed that in knee osteoarthritis, resistance exercises should be performed unilaterally with progressive load increases of $5-10 \%$. In the present study, RT involved progressive load increases of 5-10\% every 2-3 weeks for all subjects. Although this load adjustment is common in studies involving a periodized scheme, it is our understanding that a progressive pattern is also more appropriate in the treatment of knee osteoarthritis [36].
Two participants were diagnosed with lumbar discopathy, and one with cervical discopathy. Discopathy is a pathological alteration in which the annulus of the intervertebral disc is damaged, resulting in migration of the nucleus pulposus toward the spinal canal, and therefore back pain in the area around the spine and the spine itself [37]. According to Dzierżanowski et al. [37], factors associated with lumbar discopathy include physical inactivity, prolonged sitting position, overweight, and compensatory movement patterns. It is well accepted that exercise significantly improves flexibility and body posture, reduces back pain, and enhances functional capacity during daily living activities [37]. However, the above-mentioned studies [36, 37], unlike the current study, proposed RT programs that did not involve intensity increments based on RM testing. More research is needed to assess the best approach in resistance testing and training for elderly people with lumbar discopathy.

One subject was diagnosed with cervicalgia. Cervicalgia causes neck pain and has an impact on degenerative processes in the cervical vertebrae [38]. In a systematic review of the literature, Zronek et al. [39] reported that exercise programs were effective to reduce neck pain, dysfunction, and disability, and to improve quality of life. Nevertheless, the systematic review included only 2 studies that involved home RT programs. In one of them, subjects performed exercises with dumbbells ( 1 set of 15 repetitions), body weight exercises ( 3 sets of 20 repetitions), and specific isometric neck exercises (3 sets of 20 repetitions) using a rubber band [40]. In another study, subjects performed 1 set of 15 repetitions of isometric neck strengthening exercises at $80 \%$ of maximum exertion with an elastic band [41]. Thus, caution is needed when including individuals with cervicalgia in studies that involve traditional RT with moderate/high intensity loading.

One elderly woman was diagnosed with sciatica. Sciatica is characterized by radiating leg pain and related disabilities; in some cases, low back pain occurs but this is usually less severe [42]. In the majority of patients (90\%), sciatica is caused by a herniated disc with nerve root compression [42]. Nordin and Balagué [43] divided patients with severe sciatica into 2 groups. One group received symptom-guided exercises for the trunk in accordance with the McKenzie method (directional exercises), while the other group practised sham exercises not related to the back or lumbar spine. The authors reported similar and clinically significant improvements with a slight preference for the symptom-guided exercise in straight leg raising, motor function, and proprioception at the end of treat- 
ment and after a 1-year follow-up. Typically, patients will report lower limb pain, usually accompanied by dormancy and motor weakness [43]. There is limited evidence for the effectiveness of specific exercise programs in reducing leg pain when compared with the advice to simply 'stay active' [44]. More studies are needed to investigate whether traditional moderate/ high intensity RT causes more damage or benefit in patients with sciatica.

RT should be part of therapy exercises in the rehabilitation of most joint problems mentioned above [39-43]. However, exercise prescription might vary depending on the severity of injury, symptoms, cause, and level of pain in each patient. Typically, studies involving RT applied a uniform model of periodization, in which all subjects had the same intensity/volume adjustments. This traditional practice requires an adequate base of musculoskeletal conditioning, which is not always the case in elderly subjects.

To our knowledge, no adapted instrument for the recruitment of elderly people to RT was proposed previously, which also limits further comparisons. Nevertheless, this study represents an important first step in understanding the importance of physical therapy evaluation in recruiting elderly patients for research involving RT. The rationale to use the pre-exercise screening model in this study is crucial because RT has been widely applied in studies involving elderly subjects, and a large number of them employed moderate/high intensity loading. Therefore, it is necessary that researchers adopt strategies to promote the subjects' safety and good reproducibility of results, as well as to reduce the incidence of ethical complications. Physical therapy evaluation as conducted in the current study was shown to be a relevant approach for the identification of osteoarticular injuries that might be aggravated by RT. Our recommendation is that the pre-exercise screening tool for elderly individuals should be adopted when these subjects are to participate in a RT program.

Previous data have shown that a reduced ability of muscles to generate force resulting from an injury or disuse is a common impairment in the elderly [19]. If a lack of force generation by muscles is a factor inhibiting the ability to effectively perform daily activities, a rationale arises for physical therapists to apply physical therapy evaluation when designing RT programs. Guidelines are crucial for clinical recommendations, but should not replace sound clinical judgment and shared decision-making between the physician and the patient.
Moreover, the pre-exercise screening tool used in this study was adapted from previous research [23-26]. Thus, there is no necessity of validation in accordance with the Appraisal of Guidelines for Research \& Evaluation (AGREE) [45]. The AGREE tool assesses the methodological rigour and transparency in which a guideline is developed.

Considering this, these findings support the belief that with the proper use of the pre-exercise screening tool adapted in the present study, lower injury rate will occur, as demonstrated in our previous research [22]. Among 53 elderly subjects submitted to a 10 -week RT program, only two injuries occurred. These injuries did not result in serious life-threatening situations.

The pre-exercise screening tool should be applied as a filter or 'safety net' to help determine if the potential benefits of resistance exercise outweigh the risks for a subject. The inclusion of physical therapy evaluation allows some level of safety. The pre-exercise screening tool, when used as an instrument to identify and manage injury risks associated with resistance exercise, may maximize results.

A limitation of the present study was that no technical validation was applied to our adapted pre-exercise screening tool. Our intention was to suggest a safe and tested strategy to help researchers in the recruitment of elderly people to a specific type of research. The adapted pre-exercise screening tool can be aggregated with conventional anamnesis, which involves inclusion and exclusion criteria. Moreover, the tool does not exclude the necessity to implement an ergometric test, which is the most important performance test in the elderly before starting an exercise training program [2]. Future studies should evaluate the effectiveness of the pre-exercise screening tool in large population studies and other periodization models of RT.

\section{Conclusions}

Our data demonstrate that the adapted pre-exercise screening tool may have contributed to a lower injury rate in the study which was previously published by our research group [22]. In addition, the current study indicates that physical therapy evaluation prior to an RT program was a relevant strategy to identify musculoskeletal dysfunction, and the applied tool can improve the recruitment, safety, and adherence in elderly women.

\section{Acknowledgements}

We would like to thank the Laboratory for Studies in Physical Education and Health of the Catholic Uni- 
versity of Brasilia for the support of this research. The second author would like to thank his family and in particular his mother, Rita Cunha, and his son, Nicolas Cunha.

\section{Disclosure statement}

No author has any financial interest or received any financial benefit from this research.

\section{Conflict of interest}

The authors state no conflict of interest.

\section{References}

1. Skelton DA, Beyer N. Exercise and injury prevention in older people. Scand J Med Sci Sports. 2003;13(1):7785; doi: 10.1034/j.1600-0838.2003.00300.x.

2. American College of Sports Medicine. ACSM's guidelines for exercise testing and prescription. Philadelphia, Lippincott Williams \& Wilkins; 2013.

3. MacDonald HV, Johnson BT, Huedo-Medina TB, Livingston J, Forsyth KC, Kraemer WJ, et al. Dynamic resistance training as stand-alone antihypertensive lifestyle therapy: a meta-analysis. J Am Heart Assoc. 2016; 5(10):e003231; doi: 10.1161/JAHA.116.003231.

4. Pedersen BK, Saltin B. Evidence for prescribing exercise as therapy in chronic disease. Scand J Med Sci Sports. 2006;16(Suppl. 1):3-63; doi: 10.1111/j.16000838.2006.00520.x.

5. National Health Council from Brazil. Ethical review in human and social sciences research [in Portuguese]. Educ Soc. 2015;36(133):857-863; doi: 10.1590/ES010173302015v36n133ED.

6. Morrow JR Jr, DeFina LF, Leonard D, Trudelle-Jackson E, Custodio MA. Meeting physical activity guidelines and musculoskeletal injury: the WIN study. Med Sci Sports Exerc. 2012;44(10):1986-1992; doi: 10.1249/ MSS.0b013e31825a36c6.

7. Hootman JM, Macera CA, Ainsworth BE, Martin M, Addy CL, Blair SN. Predictors of lower extremity injury among recreationally active adults. Clin J Sport Med. 2002;12(2):99-106; doi: 10.1097/00042752-20020300000006.

8. Bonk J. A road map for the recruitment and retention of older adult participants for longitudinal studies. J Am Geriatr Soc. 2010;58(Suppl. 2):S303-S307; doi: 10.1111/j.1532-5415.2010.02937.x.

9. Campbell MK, Snowdon C, Francis D, Elbourne D, McDonald AM, Knight R, et al. Recruitment to randomised trials: strategies for trial enrollment and participation study. The STEPS study. Health Technol Assess. 2007;11(48):iii-105; doi: 10.3310/hta11480.

10. Goldenberg LR, Owens EF, Pickar JG. Recruitment of research volunteers: methods, interest, and incentives. J Chiropr Educ. 2007;21(1):28-31; doi: 10.7899/10425055-21.1.28.
11. Morrow-Howell N, Hong SI, Tang F. Who benefits from volunteering? Variations in perceived benefits. Gerontologist. 2009;49(1):91-102; doi: 10.1093/geront/gnp007.

12. Ross S, Grant A, Counsell C, Gillespie W, Russell I, Prescott R. Barriers to participation in randomised controlled trials: a systematic review. J Clin Epidemiol. 1999;52(12):1143-1156; doi: 10.1016/S0895-4356(99) 00141-9.

13. Burton E, Farrier K, Lewin G, Pettigrew S, Hill A-M, Airey P, et al. Motivators and barriers for older people participating in resistance training: a systematic review. J Aging Phys Act. 2017;25(2):311-324; doi: 10.1123/ japa.2015-0289.

14. Lunt H, Draper N, Marshall HC, Logan FJ, Hamlin MJ, Shearman JP, et al. High intensity interval training in a real world setting: a randomized controlled feasibility study in overweight inactive adults, measuring change in maximal oxygen uptake. PLoS One. 2014;9(1): e83256; doi: 10.1371/journal.pone.0083256.

15. Shaw CE, McCully KK, Posner JD. Injuries during the one repetition maximum assessment in the elderly. J Cardiopulm Rehabil. 1995;15(4):283-287; doi: 10.1097/00008483-199507000-00005.

16. Rhea MR, Alderman BL. A meta-analysis of periodized versus nonperiodized strength and power training programs. Res Q Exerc Sport. 2004;75(4):413-422; doi: 10.1080/02701367.2004.10609174.

17. Bredin SSD, Gledhill N, Jamnik VK, Warburton DER. PAR-Q+ and ePARmed-X+: new risk stratification and physical activity clearance strategy for physicians and patients alike. Can Fam Physician. 2013;59(3): 273-277.

18. Steiner WA, Ryser L, Huber E, Uebelhart D, Aeschlimann A, Stucki G. Use of the ICF model as a clinical problem-solving tool in physical therapy and rehabilitation medicine. Phys Ther. 2002;82(11):1098-1107; doi: 10.1093/ptj/82.11.1098.

19. Intiso D, Di Rienzo F, Russo M, Pazienza L, Tolfa M, Larossi A, et al. Rehabilitation strategy in the elderly. J Nephrol. 2012;25(Suppl. 19):90-95; doi: 10.5301/ jn.5000138.

20. Aune KT, Powers JM. Injuries in an extreme conditioning program. Sports Health. 2017;9(1):52-58; doi: $10.1177 / 1941738116674895$.

21. Freiberger E, Kemmler W, Siegrist M, Sieber C. Frailty and exercise interventions: evidence and barriers for exercise programs. Z Grontol Geriatr. 2016;49(7): 606-611; doi: 10.1007/s00391-016-1134-x.

22. Nascimento DDC, da Silva CR, Valduga R, Saraiva B, de Sousa Neto IV, Vieira A, et al. Blood pressure response to resistance training in hypertensive and normotensive older women. Clin Interv Aging. 2018;13: 541-553; doi: 10.2147/CIA.S157479.

23. Hart DL, Isernhagen SJ, Matheson LN. Guidelines for functional capacity evaluation of people with medical conditions. J Orthop Sports Phys Ther. 1993;18(6): 682-686; doi: 10.2519/jospt.1993.18.6.682. 
24. Posner JD, Gorman KM, Klein HS, Woldow A. Exercise capacity in the elderly. Am J Cardiol. 1986;57(5): 52C-58C; doi: 10.1016/0002-9149(86)91027-1.

25. Balady GJ, Chaitman B, Driscoll D, Foster C, Froelicher E, Gordon N, et al. Recommendations for cardiovascular screening, staffing, and emergency policies at health/fitness facilities. Circulation. 1998;97(22): 2283-2293; doi: 10.1161/01.CIR.97.22.2283.

26. Dalleck L, Harris N. New Zealand pre-screening guide. NZ Register of Exercise Professionals; 2014. Available from: http://www.reps.org.nz/wp-content/uploads/ 2015/04/R1663_Prescreen_v111.pdf.

27. Prestes J, Shiguemoto G, Botero JP, Frollini A, Dias R, Leite R, et al. Effects of resistance training on resistin, leptin, cytokines, and muscle force in elderly post-menopausal women. J Sports Sci. 2009;27(14):1607-1615; doi: 10.1080/02640410903352923.

28. Nascimento DDC, Tibana RA, Benik FM, Fontana KE, Ribeiro Neto F, de Santanta FS, et al. Sustained effect of resistance training on blood pressure and hand grip strength following a detraining period in elderly hypertensive women: a pilot study. Clin Interv Aging. 2014; 9:219-225; doi: 10.2147/CIA.S56058.

29. Desmeules F, Boudreault J, Roy JS, Dionne C, Fremont P, MacDermid JC. The efficacy of therapeutic ultrasound for rotator cuff tendinopathy: a systematic review and meta-analysis. Phys Ther Sport. 2015;16(3):276284; doi: 10.1016/j.ptsp.2014.09.004.

30. De Witte PB, Nagels J, van Arkel ERA, Visser CPJ, Nelissen RGHH, de Groot JH. Study protocol subacromial impingement syndrome: the identification of pathophysiologic mechanisms (SISTIM). BMC Musculoskelet Disord. 2011;12(1):282; doi: 10.1186/1471-2474-12-282.

31. Kang J-I, Moon Y-J, Choi H, Jeong D-K, Kwon H-M, Park J-S. The effect of exercise types for rotator cuff repair patients on activities of shoulder muscles and upper limb disability. J Phys Ther Sci. 2016;28(10): 2772-2777; doi: 10.1589/jpts.28.2772.

32. Van der Meijden OA, Westgard P, Chandler Z, Gaskill TR, Kokmeyer D, Millett PJ. Rehabilitation after arthroscopic rotator cuff repair: current concepts review and evidence-based guidelines. Int J Sports Phys Ther. 2012;7(2):197-218.

33. Jo CH, Lee YG, Shin WH, Kim H, Chai JW, Jeong EC, et al. Intra-articular injection of mesenchymal stem cells for the treatment of osteoarthritis of the knee: a proof-of-concept clinical trial. Stem Cells. 2014;32(5): 1254-1266; doi: 10.1002/stem.1634.

34. Gonçalves GH, Selistre LFA, Petrella M, Mattiello SM. Kinematic alterations of the lower limbs and pelvis during an ascending stairs task are associated with the degree of knee osteoarthritis severity. Knee. 2017;24(2): 295-304; doi: 10.1016/j.knee.2017.01.007.

35. Nguyen C, Lefèvre-Colau MM, Poiraudeau S, Rannou F. Rehabilitation (exercise and strength training) and osteoarthritis: a critical narrative review. Ann Phys Rehabil Med. 2016;59(3):190-195; doi: 10.1016/j.rehab.2016. 02.010 .
36. Ciolac EG, Greve JM. Muscle strength and exercise intensity adaptation to resistance training in older women with knee osteoarthritis and total knee arthroplasty. Clinics. 2011;66(12):2079-2084; doi: 10.1590/S180759322011001200013.

37. Dzierżanowski M, Dzierżanowski M, Maćkowiak P, Słomko W, Radzimińska A, Kaźmierczak U, et al. The influence of active exercise in low positions on the functional condition of the lumbar-sacral segment in patients with discopathy. Adv Clin Exp Med. 2013;22(3):421430.

38. Zeigelboim BS, Fonseca VR, Mesti JC, Gorski LP, Faryniuk JH, Marques JM. Neurotological findings at a health unit for adults with cervicalgia. Int Arch Otorhinolaryngol.2016;20(2):109-113; doi: 10.1055/s-0036-1572563.

39. Zronek M, Sanker H, Newcomb J, Donaldson M. The influence of home exercise programs for patients with non-specific or specific neck pain: a systematic review of the literature. J Man Manip Ther. 2016;24(2):62-73; doi: 10.1179/2042618613Y.0000000047.

40. Nikander R, Mälkiä E, Parkkari J, Heinonen A, Starck H, Ylinen J. Dose-response relationship of specific training to reduce chronic neck pain and disability. Med Sci Sports Exerc. 2006;38(12):2068-2074; doi: 10.1249/01.mss.0000229105.16274.4b.

41. Salo PK, Häkkinen AH, Kautiainen H, Ylinen JJ. Effect of neck strength training on health-related quality of life in females with chronic neck pain: a randomized controlled 1-year follow-up study. Health Qual Life Outcomes. 2010;8(1):48; doi: 10.1186/1477-7525-8-48.

42. Koes BW, van Tulder MW, Peul WC. Diagnosis and treatment of sciatica. BMJ. 2007;334(7607):1313-1317; doi: 10.1136/bmj.39223.428495.BE.

43. Nordin MC, Balagué F. Exercise may be beneficial for patients with chronic severe sciatica who would normally qualify for surgery. Evid Based Med. 2013;18(2): 63-64; doi: 10.1136/eb-2012-100805.

44. Ferreira ML, McLachlan A. The challenges of treating sciatica pain in older adults. Drugs Aging. 2016;33(11): 779-785; doi: 10.1007/s40266-016-0404-z.

45. Brouwers MC, Kho ME, Browman GP, Cluzeau F, Feder G, Fevers B, et al. AGREE II: Appraisal of Guidelines for Research \& Evaluation II. The AGREE Next Steps Consortium; 2013. Available from: https://www.agreetrust.org/wp-content/uploads/2013/10/AGREE-IIUsers-Manual-and-23-item-Instrument_2009_UPDATE_2013.pdf. 


\section{Appendix}

\section{ADAPTED PRE-EXERCISE SCREENING TOOL FOR THE ELDERLY}

\begin{tabular}{|l|l|}
\hline NAME: & AGE: \\
\hline RESPONSIBLE NAME AND CONTACT: &
\end{tabular}

\section{SECTION 1: MEDICAL INFORMATION}

\begin{tabular}{|c|c|c|}
\hline & YES & $\mathrm{NO}$ \\
\hline $\begin{array}{l}\text { CARDIOVASCULAR AND PULMONARY } \\
\text { CONDITIONS } \\
\text { Related or diagnosed heart condition or stroke, } \\
\text { or unreasonable chest pain during exercise? * }\end{array}$ & & \\
\hline Family history of heart disease or stroke? \# & & \\
\hline Related or diagnosed pulmonary disease * & & \\
\hline Resting blood pressure over 200/110 mmHg * & & \\
\hline $\begin{array}{l}\text { Related or diagnosed Hypertension? } \\
\text { Systolic blood pressure over } 140 \mathrm{mmHg} \text { or diastolic } \\
\text { blood pressure over 90mmHg. Or, on blood pressure } \\
\text { medication \# }\end{array}$ & & \\
\hline $\begin{array}{l}\text { MEDICATIONS: Beta blockers; ACE inhibitors; } \\
\text { Diuretic; Statin; Oral hypoglycemic; Other. }\end{array}$ & & \\
\hline $\begin{array}{l}\text { Related or diagnosed Type } 1 \text { or } 2 \text { diabetes \# } \\
\text { Glucose } \geq 5.5 \mathrm{mmol} / \mathrm{L} \text { over several readings } \\
\text { HbA1c } \geq 40 \mathrm{mmol} / \mathrm{mol}\end{array}$ & & \\
\hline $\begin{array}{l}\text { Currently smoking or quit within previous } \\
6 \text { months? \# }\end{array}$ & & \\
\hline $\begin{array}{l}\text { Physical activity level: Currently sedentary? \# } \\
\text { If no, ( ) Less than 20-min per day ( ) 20-40min } \\
\text { per day ( ) > 40min per day }\end{array}$ & & \\
\hline $\begin{array}{l}\text { Related or diagnosed obesity or overweight? \# } \\
\text { BMI } \geq 30 \mathrm{~kg} / \mathrm{m} 2 \text { or Waist }(\mathrm{cm}) \div \text { Height }(\mathrm{cm}) \text { ratio } \\
\text { above } 0.6 ?\end{array}$ & & \\
\hline $\begin{array}{l}\text { Relate pain diagnosed dyslipidemia? \# } \\
\mathrm{LDL} \geq 3.37 \mathrm{mmol} / \mathrm{L} \text {; Total } \geq 5.18 \mathrm{mmol} / \mathrm{L} ; \mathrm{HDL}< \\
1.04 \mathrm{mmol} / \mathrm{L} \text {; Triglycerides }(\mathrm{TG}) \geq 1.7 \mathrm{mmol} / \mathrm{L} ; \\
\text { TG/HDL ratio } \geq 4.0\end{array}$ & & \\
\hline \multicolumn{3}{|c|}{$\begin{array}{l}\text { * IF YOU SIGN YES ABOVE PROCEED ONLY UNDER } \\
\text { MEDICAL SUPERVISION } \\
\text { \# IF YOU SIGN YES TO } 2 \text { OR MORE ABOVE PROCEED } \\
\text { WITH CAUTION } \\
\text { Reference: Adapted from the New Zealand Pre-Screening Guide } \\
\text { (2014); Posner et al., (1986); Balady et al., (1998); American } \\
\text { College of Sports Medicine (2013) and (Hart et al., 1992). }\end{array}$} \\
\hline
\end{tabular}

\section{SECTION 2: RESISTANCE TRAINING EXPERIENCE}

Do you have any resistance training practical experience? If Yes,

( ) 1-6 months ( ) more than 1-year.

\section{SECTION 3: MUSCULOSKELETAL HISTORY}

Do you feel pain at any of joint points below?

(Please check which apply)

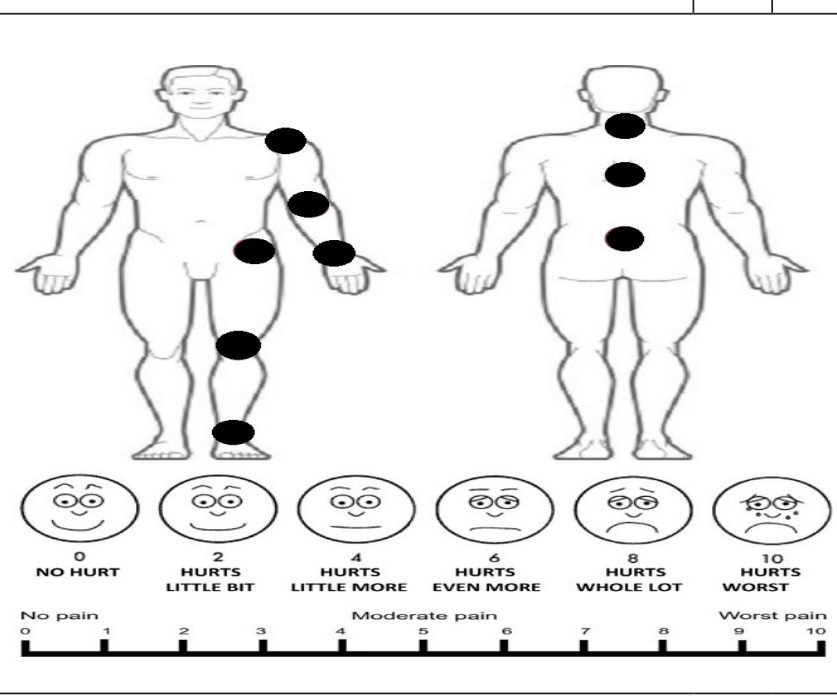

If volunteer say “yes”, what is the pain classification?

Shoulder: __ Elbow: __ ; Wrist: __ ; Hip: __ Knee: __;

Ankle: __; Lumbar: __; Thoracic: __ ; Cervical: __

\begin{tabular}{|l|l|l|}
\hline & YES & NO \\
\hline $\begin{array}{l}\text { Do you have any musculoskeletal injuries recently } \\
\text { diagnosed? e.g.: arthritis, tendinopathy. }\end{array}$ & & \\
\hline $\begin{array}{l}\text { Have you performed any surgery of the locomotor } \\
\text { system? }\end{array}$ & & \\
\hline Are you using any medication for the injury or pain? & & \\
\hline $\begin{array}{l}\text { Do you have any history of falls in recent months? } \\
\text { How many? In the street or at home? }\end{array}$ & & \\
\hline $\begin{array}{l}\text { Do you have any difficulty to perform daily living } \\
\text { activities? }\end{array}$ & & \\
\hline
\end{tabular}

\section{SECTION 4: PHYSICAL THERAPY ASSESSMENT}

Special Tests/Other physical examination procedures:

Physical Therapy diagnosis: 


\section{HUMAN MOVEMENT}

B. Saraiva et al., Physical therapy and the elderly

\section{SECTION 5: RISK STRATIFICATION AND RECOMENDATIONS}

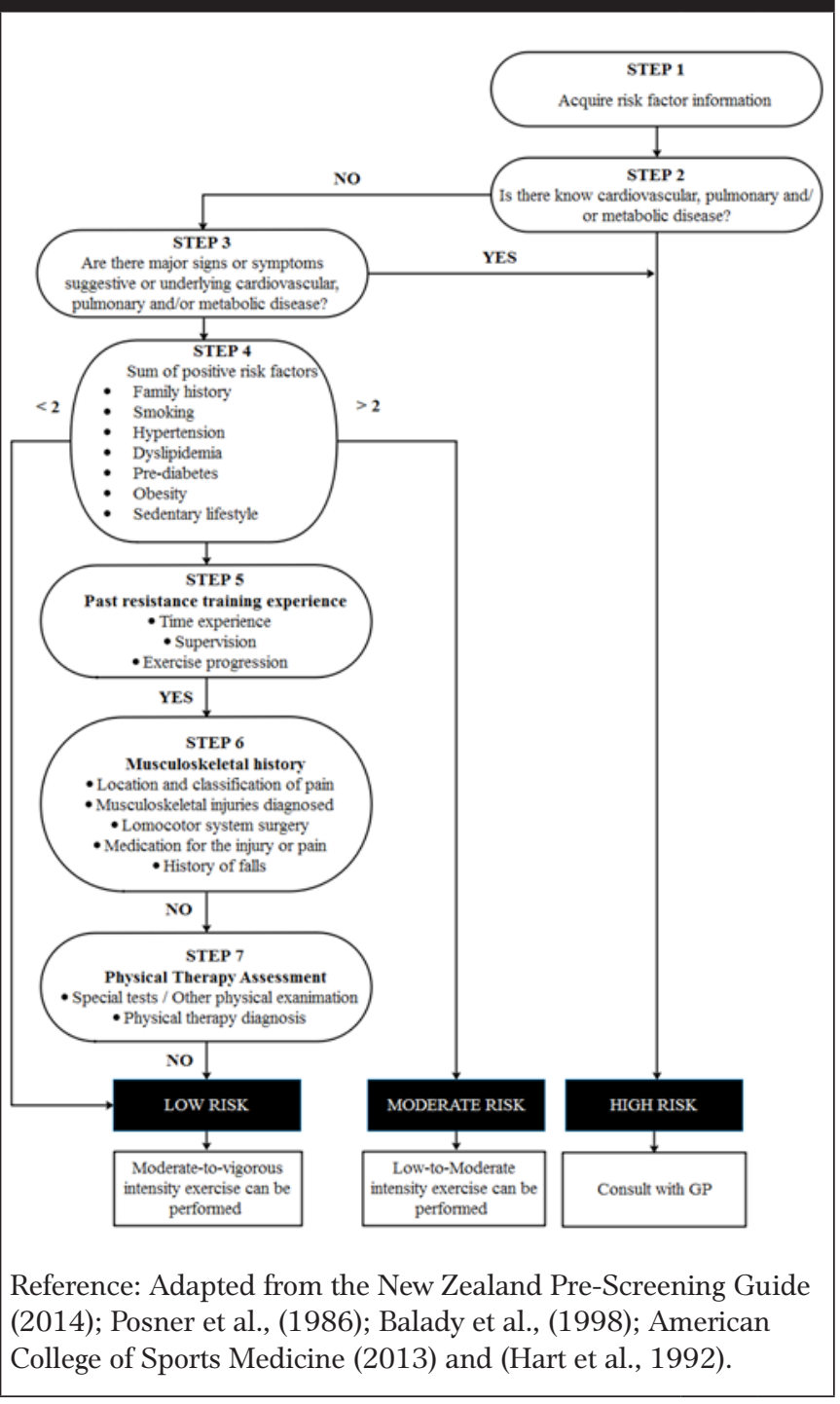

\section{Additional notes:}

Thank you for taking the time to answer the questions above.

\section{Informed Consent}

- I acknowledge that information provided above regarding my health and personal information is, to the best of my knowledge, correct.

- I will inform my exercise professional immediately if there are any changes in my health status.

- I understand that participating in resistance training program can carry a risk, and I accept all responsibility for that risk.

NAME:

SIGNATURE:

DATE: 